\title{
COPD-related morbidity and mortality after smoking cessation: status of the evidence
}

\author{
N.S. Godtfredsen*,\#, T.H. Lam \%, T.T. Hansel ${ }^{+}$, M.E. Leon ${ }^{\S}$, N. Gray ${ }^{\S, f}$, C. Dresler ${ }^{\S, * *,}$ \\ D.M. Burns ${ }^{\S, \# \#, ~ E . ~ P r e s c o t t ~}{ }^{\uparrow \uparrow}$ and J. Vestbo ${ }^{\#,++}$
}

ABSTRACT: The evidence base for the benefit of quitting smoking as regards morbidity and mortality outcomes in patients with moderate-to-severe chronic obstructive pulmonary disease (COPD) is limited.

The present article is a review of the existing literature. A systematic literature search in medical databases was performed until March 2006, and subsequently until September 1, 2007. The outcomes examined were COPD-related morbidity and mortality (including all-cause mortality) in COPD patients in connection with smoking cessation.

A total of 21 and 27 published articles on morbidity and mortality, respectively, were identified and reviewed. For both outcomes, only a few of the studies included patients with severe COPD. Most of the studies reported a beneficial effect of smoking cessation compared with continued smoking, whereas a few found no improvement. Methodological problems, including small study sizes, poor data quality, possibility of reverse causality and incomplete ascertainment of cause of death, limit interpretation of some of the studies.

The evidence as a whole supports the conclusion that, even in severe chronic obstructive pulmonary disease, smoking cessation slows the accelerated rate of lung function decline and improves survival compared with continued smoking.

KEYWORDS: Chronic obstructive pulmonary disease, morbidity, mortality, review, smoking cessation

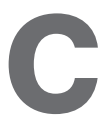
hronic obstructive pulmonary disease (COPD), which is considered an inflammatory disease with pulmonary and systemic components, is predominantly found in patients with a history of cigarette smoking and has an enormous and increasing global health impact [1]. According to the World Health Organization (WHO), 80 million people worldwide have moderate-to-severe COPD. In 2005, three million deaths due to the disease were reported, and the WHO predicts that, by the year 2030, COPD will have become the third leading cause of death [2]. Previously, COPD has been regarded as a progressive irreversible disease with a poor prognosis, but, in the current international guidelines (Global Initiative for Chronic Obstructive Lung Disease (GOLD) and American Thoracic Society/European Respiratory Society), COPD is defined as a modifiable and treatable disease [3,4]. Nevertheless, apart from long-term oxygen treatment in COPD patients with severe hypoxaemia and smoking cessation in patients with mild-to-moderate lung function impairment, to date, no treatment has convincingly been able to influence the accelerated lung function decline or increased mortality characterising this disease [5].

The effect of smoking cessation on outcomes, such as respiratory symptoms, lung function, airway hyperresponsiveness and inflammation, has recently been reviewed [6].

The clinical course of COPD, determined as a continuous excessive loss of ventilatory capacity, is an important and well-established outcome measure. The long-term benefit of sustained and, to a lesser extent, intermittent smoking cessation as regards forced expiratory volume in one second (FEV1) in patients with mild-to-moderate COPD has been convincingly demonstrated in

\section{AFFILIATIONS}

${ }^{*}$ Copenhagen Centre for Prospective Population Studies, Institute of Preventive Medicine,

${ }^{\#}$ Dept of Cardiology and Respiratory Medicine, Hvidovre Hospital and Faculty of Health Sciences, University of Copenhagen, and "Dept of Cardiology, Bispebjerg University Hospital, Copenhagen, Denmark.

"Dept of Community Medicine, School of Public Health, University of Hong Kong, Pokfulam, Hong Kong. ${ }^{+}$National Heart and Lung Institute, Imperial College, London, and ${ }^{++}$North West Lung Centre, Wythenshawe Hospital, Manchester, UK.

${ }^{\S}$ International Agency for Research on Cancer, Lyon, France.

${ }^{f}$ Cancer Council, Victoria, Australia

**Arkansas Dept of Health, Little Rock, AR, and

\#\#School of Medicine, University of California at San Diego, San Diego, CA, USA.

\section{CORRESPONDENCE}

N.S. Godtfredsen, Dept of Respiratory Medicine, Bispebjerg Hospital, DK2400 Copenhagen NV, Denmark.

Fax: 4535312865

E-mail:ngod0001@bbh.regionh.dk

Received:

November 272007

Accepted after revision:

May 252008

SUPPORT STATEMENT

This study was supported by the

Danish Ministry of Health

(Copenhagen, Denmark)

European Respiratory Journal

Print ISSN 0903-1936

Online ISSN 1399-3003 
the Lung Health Study (LHS) [7-9]. At the 11-yr follow-up, $38 \%$ of the continuing smokers had an FEV 1 of $<60 \%$ of the predicted normal value compared to $10 \%$ of sustained quitters [8]. However, for patients with clinically significant disease, i.e. usually severe COPD, the impact of quitting smoking on health-related outcomes, such as hospital admission due to exacerbations with or without respiratory infection or mortality due to COPD, has not been thoroughly examined. The US Surgeon General's Report from 1990 on the health benefits of smoking cessation evaluated the effect of smoking cessation on FEV1 decline and COPD mortality in the general population and COPD patients [10]. At that time, however, there were only three published studies assessing smoking cessation and FEV1 decline in COPD patients, and a further three studies of mortality among COPD patients.

The aim of the present review is to present and discuss the currently available evidence of reduced risk of COPD-related morbidity and mortality following smoking cessation. Given the large differences in both the tobacco epidemic and the natural history of COPD between Western countries and Asia, results from the four Chinese cohort studies that examined the effect of quitting smoking on all-cause mortality and mortality due to COPD are also presented.

\section{MATERIALS AND METHODS}

The present review is based on a contribution to the International Agency for Research on Cancer's 11th Handbook of Cancer Prevention, the first in a series on Tobacco Control entitled Reversal of Risk After Quitting Smoking [11]. An international working group of experts met in Lyon (France) in March 2006 to revise earlier drafts, discuss and form conclusions concerning the effects of quitting smoking on the risk of developing COPD, cardiovascular disease and cancer. A systematic literature search was performed until March 12, 2006 in PubMed, EMBASE and personal databases for articles in English containing the following keywords: COPD, smoking cessation, quitting smoking, ex-smoking, former smoking, mortality, death, morbidity, hospitalisation, health status, prognosis, and lung function (including decline in FEV1). Additional searches were performed regularly until September 1, 2007, and a few further studies were identified from the reference lists of the included articles.

\section{Study limitations}

For the present review, only concrete end-points, such as FEV1 decline, hospital admission due to COPD exacerbation, allcause mortality and mortality due to COPD, were chosen. A number of studies with identical outcomes were, however, not readily comparable for a variety of reasons.

For instance, it seems fair to state that many of the early studies of smoking cessation did not control adequately for smoking habits, i.e. they did not calculate cumulative exposure in terms of pack-years or measure duration of smoking or time since smoking cessation. Regarding the studies with a morbidity outcome, it is worth noting that negative results (no effect of smoking cessation) only occurred in the few studies that were cross-sectional or had the shortest duration of follow-up. However, in the majority of studies, measuring an absolute decrease in lung function expressed as annual loss in millilitres, the internal validity was intact, whereas the decline rate could not be compared across studies. In the studies with a mortality outcome, the problems with a short follow-up became even more crucial since reverse causality (increased mortality due to quitting smoking in response to pre-existing illness) was introduced. This was evident in the Chinese studies, in which the additional fact that the smoking attributable risk of COPD is not as large as in Western countries seemed to play a role in the results. Furthermore, in these types of research, clinical trials can be subject to selection bias and population-based studies imply a risk of residual confounding, i.e. differences between ex-smokers and continuing smokers in baseline risk of study outcome. These issues are discussed further in the Discussion section.

\section{RESULTS \\ Morbidity}

A total of 21 articles (17 studies) on either COPD patients or subjects with airway obstruction not attributed to asthma were identified [8, 12-31]. The outcomes examined were FEV1 decline, hospitalisation due to COPD and self-reported respiratory illness. All of the studies are listed in table 1, with comments where necessary. Where applicable, the percentage reduction in FEV1 decline in ex-smokers compared with continuing smokers is displayed in figure 1.

\section{Clinically based studies}

In the 1990 US Surgeon General's report, only three studies concerning the effect of smoking cessation on FEV1 decline in patients with established COPD were evaluated [12-14]. Postma et al. [14] studied a group of 81 patients with moderate-to-severe COPD followed for 2-21 yrs. The 22 patients who stopped smoking at enrolment or during the study experienced a change $(\Delta)$ in FEV1 of $-49 \pm 7 \mathrm{~mL} \cdot \mathrm{yr}^{-1}$, which is faster than the mean decline in never-smokers in the general population, whereas the sustained smokers declined with a $\triangle$ FEV1 of $-85 \pm 5 \mathrm{~mL} \cdot \mathrm{yr}^{-1}$. Another study followed 56 males with emphysema for 3-13 yrs in order to assess $\triangle \mathrm{FEV} 1$ in smokers and ex-smokers [13]. Of the 19 ex-smokers, twothirds had stopped smoking $<2$ yrs before study entry. Duration of smoking and cumulative tobacco consumption were equal in the two groups. $\triangle F E V 1$ was $-15 \pm 6.7 \mathrm{~mL} \cdot \mathrm{yr}^{-1}$ in the ex-smokers and $-57.7 \pm 6.0 \mathrm{~mL} \cdot \mathrm{yr}^{-1}$ in the continuing smokers. In contrast, the Intermittent Positive-Pressure Breathing (IPPB) Trial did not find any differences in FEV1 decline between ex- and current smokers in a group of 985 patients with moderate-to-severe COPD [12].

Fletcher and Peto [15] stratified their sample comprising 792 working males according to presence of mild airway obstruction, and found $\triangle F E V 1$ values of $-37,-62$ and $-80 \mathrm{~mL} \cdot \mathrm{yr}^{-1}$ in quitters, light smokers and heavy smokers, respectively. In a small smoking cessation trial lasting 30 months, BuIsT et al. [16] found that subjects with impaired lung function at baseline showed greater improvement in percentage predicted FEV1 following smoking cessation than subjects with normal lung function at baseline. However, this analysis was based on only seven participants, and possible asthma was not ruled out (data not shown in table 1).

Since the 1990 report, only a few additional studies in clinical settings have emerged. In the LHS, a landmark study of smoking cessation in mild-to-moderate COPD, there was no 


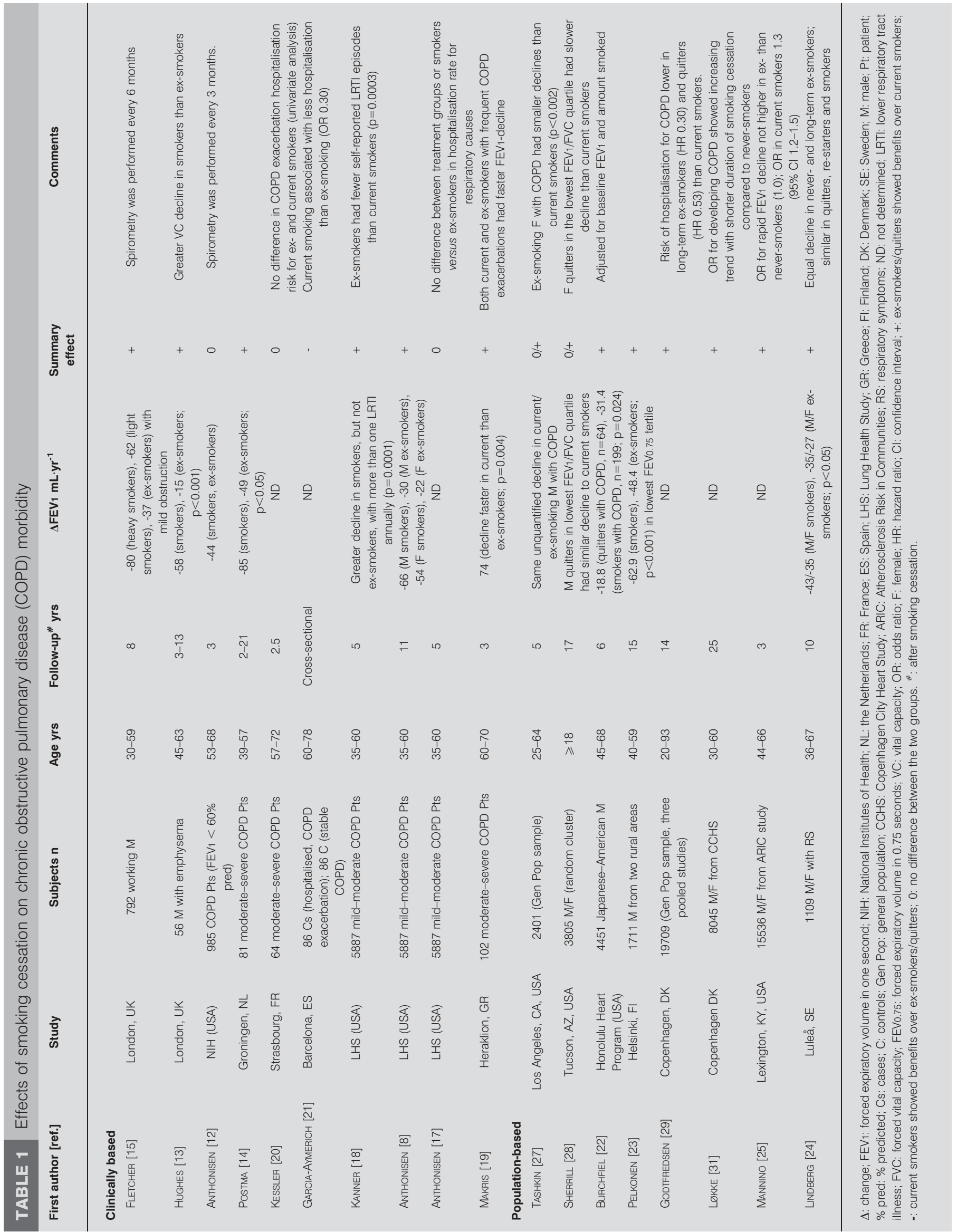




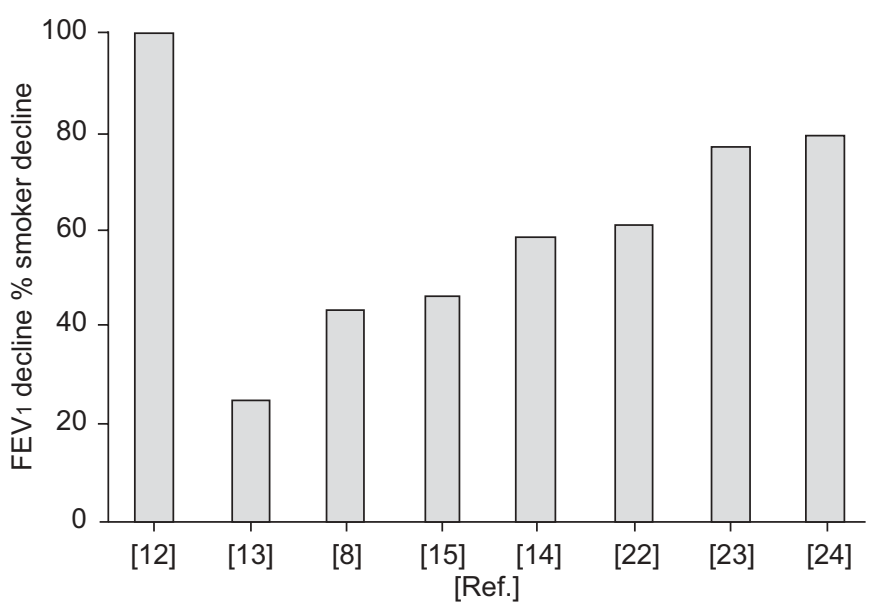

FIGURE 1. Forced expiratory volume in one second (FEV1) decline expressed as a percentage of the decline in $100 \%$ of continuing smokers in those studies for which this measure was available. All but one of these studies show a relative reduction in $\mathrm{FEV} 1$ decline.

difference between the quitters and continuing smokers with respect to hospitalisation due to respiratory disease [17]. The authors attributed this result to the short follow-up and the few cases of hospital admission due to a respiratory condition. However, an earlier article from the same study reported that, compared with current smokers, ex-smokers exhibited fewer episodes of self-reported lower respiratory tract illness, and that the rate of FEV1 decline was negatively affected by lower respiratory tract illness in smokers alone [18]. Recently, a prospective study from Crete in a group of elderly outpatients with moderate-to-severe COPD found accelerated FEV1 decline in the 44 continuing smokers compared with the 58 ex-smokers [19]. A further two studies have assessed smoking habits and risk of hospital admission for COPD exacerbation. A French study of 64 patients with moderate-to-severe COPD found, on univariate analysis, that the risk of hospital admission for an exacerbation of COPD did not differ between ex- and current smokers [20]. In a case-control design, the Risk Factors of COPD Exacerbation Study (EFRAM) found that current smoking was negatively associated with hospitalisation compared to ex-smoking [21], an unexpected finding, which the authors interpreted as a probable ill-quitter (smokers who quit because they become ill) effect.

Population-based studies

In the Honolulu Heart Program, separate analyses were performed in 216 males with impaired lung function, determined to either be in the lowest baseline FEV1 tertile or have a low z-score [22]. The 17 males who quit within the first 2 yrs of the 6-yr study exhibited a slower decline in FEV1 than those who continued to smoke $(\triangle \mathrm{FEV} 1-1.8$ versus $\left.-31.4 \mathrm{~mL} \cdot \mathrm{yr}^{-1}\right)$, whereas this was not the case in the 47 males who quit $0-4$ yrs before follow-up $(\triangle \mathrm{FEV} 1-25.1$ versus $\left.-31.4 \mathrm{~mL} \cdot \mathrm{yr}^{-1}\right)$. The study also indicated that participants in the lower or middle FEV1 tertile benefited more from quitting than those with the best lung function. More recently, the 30-yr follow-up data from the Finnish cohorts of the Seven Countries Study confirmed that quitting smoking during the study was associated with a slower FEV1 decline across all FEV1 tertiles compared with continuing smokers [23]. A recently published paper from the Obstructive Lung Disease in Northern Sweden (OLIN) studies analysed FEV1 decline in a cohort with respiratory symptoms [24]. Lung function decline in persistent ex-smokers did not differ significantly from that in neversmokers, but male quitters, re-starters and persistent smokers of both sexes showed a faster decline and at a mutually similar rate.

The Atherosclerosis Risk in Communities study analysed risk factors for and outcomes of rapid FEV1 decline in a large cohort from the USA [25]. Current smokers showed a greater risk of rapid decline at the 3-yr spirometric follow-up compared with never-smokers, whereas former smokers showed the same risk as never-smokers. The authors repeated the analysis in another smaller cohort aged $\geqslant 65$ yrs and found similar results (data not shown in table 1) [26]. Conversely, the University of California at Los Angeles study did not find any difference in FEV1 decline between male quitters and continuing smokers with airflow obstruction, but female quitters with obstruction exhibited a slower decline than continuing smokers [27]. However, it is not clear whether this subset analysis was controlled for cumulative tobacco exposure. The same trend was found among males and females in the lowest FEV1/forced vital capacity (FVC) quartile in the Tucson study, which had a longer duration of follow-up, but, again, the level of adjustment in the statistical models was not explicit [28].

A study from Copenhagen (Denmark) pooling three populationbased studies analysed changes in smoking habit and risk of a first hospital admission due to COPD and found a gradient of relative risk (RR) with increasing tobacco exposure [29]. Compared with continuing smokers, the RR estimates were 0.30 (95\% confidence interval $0.18-0.50$ ) for ex-smokers prior to study entry, $0.40(0.29-0.55)$ for those smoking $<15$ cigarettes $\cdot$ day $^{-1}$ at baseline who quit during the study and $0.66(0.47-0.93)$ for those smoking $>15$ cigarettes $\cdot$ day $^{-1}$ at baseline who quit during the study. Smokers belonging to the lowest FEV1 tertile also benefited from quitting smoking. Recently, other results from the OLIN studies (data not shown in table 1) and the Copenhagen City Heart Study confirmed that the risk of acquiring COPD according to either British Thoracic Society or GOLD criteria decreased with increasing time since smoking cessation $[30,31]$.

\section{Mortality}

The present review identified 27 articles (24 studies) on smoking habits and mortality [12, 17, 32-56], of which only six included exclusively subjects with COPD. The studies are listed in table 2. Figure 2 displays the RR of mortality due to COPD in ex-smokers compared with continuing smokers, and figure 3 shows the risk of all-cause mortality in ex-smokers compared with persistent smokers.

Since poor lung function is an independent predictor of allcause mortality [57] and there are well-known difficulties in ascertainment of COPD as the principal cause of death [58], it was decided to include articles with mortality due to both all causes and COPD as outcomes. The 1990 US Surgeon General's report evaluated studies of the effect of smoking cessation on mortality from all causes and COPD mortality in the general population and COPD patients. In these studies, the absolute reductions in mortality risk after quitting smoking ranged 32 $84 \%$ compared with continuing smokers, and were highly 
TABLE 2 Effects of smoking cessation on all-cause and chronic obstructive pulmonary disease (COPD) mortality

\begin{tabular}{|c|c|c|c|c|c|}
\hline First author [ref.] & Study & Subjects n & $\begin{array}{c}\text { Follow-up } \\
\text { yrs }\end{array}$ & $\begin{array}{l}\text { Mortality } \\
\text { outcome }\end{array}$ & $\begin{array}{c}\text { Summary } \\
\text { effect }\end{array}$ \\
\hline
\end{tabular}

\section{Clinically based}

POSTMA [34]

USA

140 Utah COPD Pts

7-13

All-cause

All-cause

Groningen, NL

129 severe COPD Pts

985 COPD Pts aged 53-68 yrs

$139 \mathrm{M}$ severe COPD Pts aged

$$
<53 \text { yrs }
$$

ANTHONISEN [17]

LHS (USA) $\quad 5887 \mathrm{M} / \mathrm{F}$ smokers with early COPD

(FEV $155-90 \%$ ) aged 35-60 yrs

ANTHONISEN [35]

USA

$5887 \mathrm{M} / \mathrm{F}$ smokers with early COPD

(FEV $155-90 \%$ ) aged $35-60$ yrs

Population-based

DoLL [56]

Rogot [32]

UK

USA

CARSTENSEN [39]

SE

MARCUS [41]

Honolulu Heart Program (USA)

TOCKMAN [42]

USA

$6194 \mathrm{~F}$ doctors

ح200000 M US veterans

25129 M

11136 Japanese-American

$\mathrm{M}$ aged 45-

$65 \mathrm{yrs}$ at enrolmen

$36110 \mathrm{M} / \mathrm{F}$ aged $35-84$ yrs from

private census Pop, examined in

two 6-yr periods

$884 \mathrm{M}$ with FEV1 measures (subse

of above)

KULLER [40]

LANGE [45]

USA

DK

$12866 \mathrm{M}$ from MRFIT

$14214 \mathrm{M} / \mathrm{F}$ from $\mathrm{CCHS}$

10
13

All-cause

COPD

TVERDAL [43]

NO

BEN-SHLOMO [38]

$68000 \mathrm{M} / \mathrm{F}$ aged 35-49 yrs

13 (mean)

All-cause

19018 M from Whitehall Study

18

$477 \mathrm{M}$ from Barcelona aged $>65 \mathrm{yrs}$

$\mathrm{COPD}$

SUNYER [44]

KNUIMAN [48]

$\mathrm{AU}$

$4277 \mathrm{M} / \mathrm{F}$ from the Busselton Health Study

ENGSTROM [49]

Pelkonen [46]

291 smoking M born 1914

1582 middle-aged M

14
30

30

ev

GODTFREDSEN [47]

DK

19732 M/F from 3 Copenhagen Pop 15.5 (mean) studies

All-cause

COPD

MANNINo [50]

USA

5542 M/F aged 25-74 yrs from NHANES

DOLL $[37,55]$

UK

34439 M UK doctors

40,50

COPD

\section{Chinese}

Ho [51]

LAM [53]

Hsu [52]

LAM [54]
HK

HK

TW

HK
$2030 \mathrm{M} / \mathrm{F}$ aged $\geqslant 70 \mathrm{yrs}$

1268 retired male cadres aged $\geqslant 60 \mathrm{yrs}$

$4049 \mathrm{M} / \mathrm{F}$ aged $\geqslant 60 \mathrm{yrs}$
$56167 \mathrm{M} / \mathrm{F}$ aged $\geqslant 65 \mathrm{yrs}$
In a case-control design (sex- and age-matched Pop), 12-y survival probabilities were 86,79 and $64 \%$ in never-,

$$
\text { ex- and current smokers, respectively }
$$

Pts were stratified according to bronchodilator reversibility; relative survival was higher in both current- and ex-smokers with greater reversibility; within each stratum, mortality was lower in ex- than current smokers Overall mortality was $23 \%$

(no difference between current and ex-smokers)

Recent smoking status predicted mortality independently of the effects of lifetime smoking intensity;

Pts who were ex-smokers at enrolment had better survival than smokers

There were 149 deaths during the study, caused largely

by lung cancer and CVD; smoking cessation was associated with

significant reductions in fatal CVD and coronary artery disease (too few COPD deaths for analysis)

After 14.5 yrs of follow-up, 731 patients had died;

all-cause/respiratory MR was significantly lower in

the special intervention group than in the usual care group

COPD MRs lower in ex- than current smokers

( 5.0 versus $10.5-32.0 \%$ (depending on amount smoked))

COPD MRs higher in ex- than current smokers until $10 \mathrm{yrs}$

after smoking cessation; thereafter lower MRs in ex- than current smokers ( 5.2 versus $12.1 \%$ )

COPD MRs lower in ex- than current smokers

( 1.8 versus $1.9-5.3 \%$ (depending on amount smoked))

Age-specific COPD MRs calculated at 5-yr intervals (1965-1984); after 10 yrs, MRs were higher in ex- than never- and current smokers; after $\geqslant 15 \mathrm{yrs}$, MRs were similar in never- and ex-smokers and lower than current smokers $M$ MRs due to both all causes and COPD were greater in exthan never-smokers, but lower than MRs for current smokers $(p<0.05)$; this applied to both time periods;

same trend for $\mathrm{F}$, but too few COPD deaths in ex-smokers for analysis. Normal FEV 1 : OR 1 (never-smokers), 1.75 (ex-smokers), 4.80 (current smokers):

FEV $1<65 \%$ pred: OR 3.71 (never-smokers), 6.50 (ex-smokers), 17.80 (current smokers)

Lower all-cause MR in ex- than current smokers

Compared to never-smokers, RR of COPD mortality in

F ex-smokers was 11 (95\% Cl 2.5-53), current smokers 15 (95\% Cl 3.1-65); RR in M ex-smokers was

3.0 (95\% Cl 0.9-10), current smokers 6.4 (95\% Cl 2.0-20)

MRs for ex-smokers were intermediate to rates

for never-smokers and smokers in both $\mathrm{M}$ and $\mathrm{F}$

Annual COPD MRs in never-, ex- and current

smokers were $0.68,0.95$ and 2.2 per thousand study population

There were similar prevalences of self-reported respiratory

illness in ex- and current smokers, and similar annual

COPD MRs ( 6.0 versus 1.7 per thousand study population in never-smokers)

Per $10 \%$ decrease in FEV 1 , HR of all-cause mortality was 1.195 (95\% Cl 1.124-1.271)

in ex-smokers and $1.167(95 \% \mathrm{Cl} 1.108-1.229)$ in current smokers compared to neversmokers

CV MRs in current- and ex-smokers similar by FEV 1 decline tertile

Compared to current smokers, there was lower total mortality in neversmokers, long-term ex-smokers and quitters:

RR of COPD mortality in ex-smokers was 2.51 ( $95 \% \mathrm{Cl} 0.65-9.70)$ compared to current smokers.

RR of COPD mortality after smoking cessation was

0.77 (95\% Cl 0.44-1.35) compared to current smokers:

$\mathrm{HR}$ of all-cause mortality was $0.65(95 \% \mathrm{Cl} 0.56-0.74)$

no comparison was made with never-smokers

$\mathrm{HR}$ of all-cause mortality in a multivariate adjusted model was 1.1 in ex-smokers (95\% $\mathrm{Cl} 0.9-1.4)$

1.4 in current smokers $(95 \% \mathrm{Cl} 1.2-1.7)$

COPD MRs in ex-smokers were intermediate between those of

never-smokers and current smokers; RR of all-cause mortality

lower in ex- than current smokers (1.3 versus 2.2$)$

Similar all-cause MRs in ex- and current smokers; higher rate of respiratory mortality in $\mathrm{F}$ ex-smokers (RR 2.3 (95\% Cl 1.3-4.0)) RR of COPD mortality $2.13(95 \% \mathrm{Cl} 0.55-8.30)$

in current smokers; 4.10 (95\% Cl 1.18-14.28) in ex-smokers

No differences between ex- and current smokers for all-cause or cause-specific mortality; this study does not meet standard quality criteria

RR of all-cause mortality in ex-smokers was 1.39 (95\% Cl 1.23-1.56) in $\mathrm{M}$ and 1.43 (95\% $\mathrm{Cl} 1.25-1.64)$ in $\mathrm{F}$;

rates were significantly higher in current smokers; COPD MRs were higher in ex- than current smokers

NL: the Netherlands; LHS: Lung Health Study; SE: Sweden; DK: Denmark; NO: Norway; ES: Spain; AU: Australia; FI: Finland; HK: Hong Kong; TW: Taiwan; Pt: patient; M: male; F: female; FEV1: forced expiratory volume in one second; Pop: population; MRFIT: Multiple Risk Factor Intervention Trial; CCHS: Copenhagen City Heart Study; NHANES: National Health and Nutrition Examination Survey; CV: cardiovascular; CVD: cardiovascular disease; MR: mortality rate; OR: odds ratio; \% pred: \% predicted; RR: relative risk; Cl: confidence interval; HR: hazard ratio; +: risks lower in ex-smokers than smokers (benefits of quitting); -: risks highe in ex-smokers than smokers; 0: risks similar in ex-smokers and smokers; ?: results not clear. ${ }^{*}$ : after smoking cessation; " $:$ RR and HR of never-smokers (reference group) $=1.0$. 


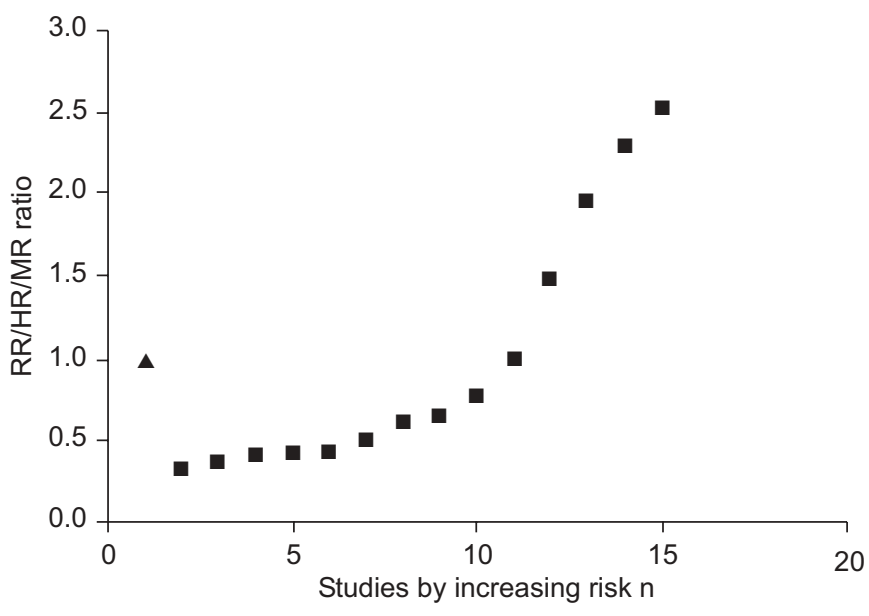

FIGURE 2. Relative risk (RR)/hazard ratio (HR)/mortality rate (MR) ratio of mortality due to chronic obstructive pulmonary disease after smoking cessation ( compared with continuing smoking ( $\mathbf{\Lambda} ; \mathrm{RR} 1.0)$.

dependent upon duration of smoking and amount smoked [10]. A number of the studies analysed COPD mortality in exsmokers by time since quitting smoking. Even in apparently healthy quitters, the risk of dying due to COPD remained higher than in continuing smokers for up to 10 yrs following tobacco abstinence, and mortality risk was also permanently elevated compared with never-smokers [32]. With respect to mortality in patients already diagnosed with COPD, the report stated that no conclusions could be made due to the limited evidence available.

\section{Clinically based studies}

Of the four studies included in the 1990 report, only the two studies with a substantial duration of follow-up, the Utah study of KANNER et al. [33] and the Dutch study of POSTMA et al. [34], suggested increased survival probability in COPD patients who quit smoking. The IPPB Trial found similar mortality rates in current- and ex-smokers; however, the follow-up lasted only 3 yrs. Recently, the LHS published its 14.5-yr mortality results [35]. Mortality due to respiratory disease other than cancer constituted $7.8 \%$ of all deaths, and mortality rates due to these diseases were significantly lower in the intervention than in the usual care group. Furthermore, respiratory disease mortality was lowest in sustained quitters, highest in continuing smokers and intermediate in intermittent quitters. Finally, a study from Boston (MA, USA) of 139 patients aged $<53$ yrs with very severe COPD, who were followed for up to $8 \mathrm{yrs}$, showed that cumulative tobacco consumption and active smoking after enrolment were associated with poorer survival [36], whereas ex-smoking at study entrance implied better survival.

\section{Population-based studies}

After 40 yrs of follow-up in male UK doctors, DolL et al. [37] found that mortality rates due to COPD in former smokers lay between those of never- and current smokers. Similar results were found in the study of US veterans, the Whitehall Study, a large Swedish study, the Multiple Risk Factor Intervention Trial, the Honolulu Heart Program and a large study from Washington County [32, 38-42]. A large Norwegian study that

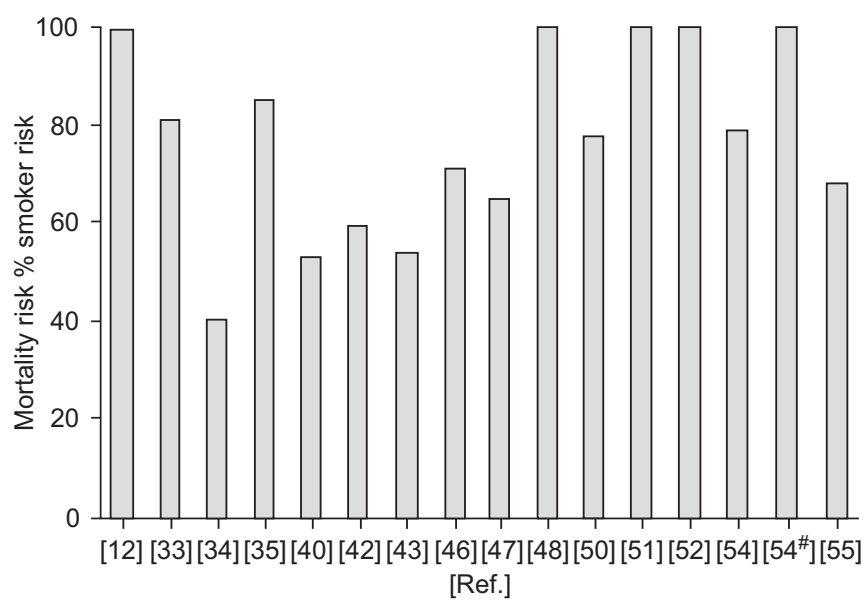

FIGURE 3. Risk of all-cause mortality after smoking cessation expressed as a percentage of the risk in $100 \%$ of continuing smokers. The majority of these studies show a reduction in risk. ${ }^{\#}$ : females alone.

followed a cohort of males and females initially aged 35-49 yrs for 13 yrs showed that mortality rates due to respiratory disease were almost equal in never- and ex-smokers [43]. By contrast, the study from Finland, a Spanish study of males aged $\geqslant 65$ yrs and the Copenhagen City Heart Study found similar COPD mortality rates in quitters and continuing smokers [44-46]. However, in the latter study, this was only seen in females, and there were few deaths from COPD in any of the studies. Results from a pooled analysis of population studies in Denmark showed an increase in mortality rates due to respiratory disease with fewer years since quitting and a greater amount smoked [47]. However, only all-cause mortality rates were significantly lower in ex-smokers than in current smokers, as was the case in the Finnish study.

Four studies have analysed mortality specifically in relation to lung function and smoking habits. The Busselton Health Study from Australia analysed mortality per $10 \%$ decrease in FEV1 and found increased all-cause mortality in male ex-smokers (highest) and current smokers compared with never-smokers [48]. Analyses of overall mortality in females and of respiratory disease mortality in both sexes were nonsignificant, most probably due to lack of power. A small cohort study from Sweden found quite similar cardiovascular mortality rates in exand current smokers by FEV1 decline tertile, but the smoking groups were not compared with each other [49]. A study in a subset of the census population in Washington County (OR, USA) comprising 884 males found elevated all-cause and COPD mortality rates across all smoking strata in males with an FEV1 of $<65 \%$ pred, with the rates for ex-smokers lying between those of never- and current smokers [42]. A recent study from the First National Health and Nutrition Examination Survey, with a long duration of follow-up, found that the all-cause mortality rate in former smokers did not differ significantly from that in neversmokers, whereas it was increased in current smokers [50].

\section{Chinese studies}

There are few mortality studies from China [51-54], and all are population-based. There are no studies addressing COPD morbidity. Study participants were all aged $\geqslant 60$ yrs, follow-up 
was generally short, and only one recent study was large $(56,167$ subjects). All studies showed that COPD mortality rates were higher in ex- than never- and current smokers, but the large cohort study from elderly health centres in Hong Kong followed for 3.2-5.0 yrs found that RRs of all-cause mortality in ex-smokers lay between those of never- and current smokers [54].

\section{DISCUSSION}

\section{Morbidity}

With $\sim 20$ published papers specifically addressing smoking cessation and some aspect of COPD morbidity as outcome since the mid-1970s, the evidence, on which smoking cessation recommendations in COPD patients are based, is truly not proportionate to the degree of morbidity caused by smoking. Furthermore, only half of the studies have analysed loss of lung function as the primary outcome, and these studies vary considerably with respect to definition and severity of COPD, duration of smoking cessation and methodology in general. Some studies have employed a proxy for COPD, i.e. they did not define the disease but rather analysed subjects with respiratory symptoms or those with the lowest baseline FEV1; however, these measures are not necessarily appropriate as disease markers. Despite the study dissimilarities, they nearly all show significantly attenuated FEV1 decline in exsmokers or quitters compared with continuing smokers, suggesting a clear benefit of smoking cessation, even in the few studies that included patients with more severe disease. Some exceptions were found in three of the earliest studies from the USA $[12,27,28]$, in two of which a favourable effect of smoking cessation on lung function loss was found only in females [27, 28]. It is not clear, though, whether detailed adjustment for smoking habits in males and females was performed in these studies. With hospital admission for COPD exacerbation or analysis of development of severe/very severe COPD (GOLD stage 3-4), it must be assumed, apart from the possible inaccuracies in disease coding on discharge records, that these events occur in patients with severe disease. After 5 yrs of follow-up in the LHS and 2.5 yrs in a small study from France, and cross-sectionally in the Spanish EFRAM, there were no differences in risk of hospitalisation due to COPD between current and ex-smokers [17, 20, 21]. In contrast, the population-based studies from Denmark and Sweden, with longer duration of follow-up, showed lower risk of these outcomes after quitting smoking compared to that found in continuing smokers [29, 30], but the results were highly dependent upon the duration of smoking cessation.

Findings from the morbidity studies illustrate the complexities in assessing the potential benefits of quitting smoking in COPD patients. Smoking cessation in mild-to-moderate disease can prevent progression of disease severity; however, it is not known what characterises smokers with different stages of COPD who choose to stop smoking compared with those who continue. Possible biases towards not finding a beneficial effect of smoking cessation include so-called reverse causality (illquitter or healthy smoker effect). In cohort studies, residual confounding and changes in smoking status during long-term follow-up can affect the associations between exposure and outcome. Furthermore, several recent bronchial biopsy studies have shown that airway inflammation persists in ex-smoking COPD patients [59], which is likely to affect disease course. In contrast, the effect of smoking cessation can be overestimated in hospital admission or incidence studies if current smokers are more likely than ex-smokers to obtain a discharge diagnosis of COPD or to undergo spirometry. Finally, it is difficult to conduct a large cohort study primarily aimed at smoking cessation intervention in patients with severe COPD due to the high rate of cessation in these populations, except in populations in whom smoking cessation intervention is seldom practised, such as in China. The largest study of severe COPD patients presented in this review, the IPPB Trial, included patients with a pre-bronchodilator FEV1 of $<60 \%$ pred, but without chronic respiratory failure. The investigators attributed their null results with respect to smoking status, FEV1 decline and mortality to the ill-quitter effect and the short duration of follow-up [12]. Since the early 1990s, efforts in treatment of COPD have, among other initiatives, concentrated on inhaled bronchodilators and/or inhaled corticosteroids (ICSs), making it more complicated to disentangle the effects of smoking cessation and pharmacological therapy in the many randomised trials that have been conducted in this area. The newly published Towards a Revolution in COPD Health (TORCH) trial [60], which had approximately the same inclusion criteria and duration as study of ANTHONISEN et al. [12], but with $>6,000$ patients, stratified the survival analyses according to baseline smoking status, possibly to avoid interaction between smoking status and pharmacological therapy. Of the study population, $43 \%$ were current smokers at baseline, and change in FEV1 was assessed every 24 weeks by post-bronchodilator spirometry in the four treatment arms, but smoking status at the follow-up visits was not taken into account in these analyses.

\section{Mortality}

From table 2, it appears that the vast majority of the mortality studies have been performed in healthy populations. Eight of the retrieved papers analysed all-cause mortality alone, nine studies had mortality due to COPD as the sole outcome and seven studies analysed both outcomes. With a few exceptions (studies with short follow-up and the Chinese studies), the results indicate that mortality rates due to all causes and COPD decline progressively after smoking cessation compared with continuing smoking, but that mortality risk in ex-smokers is still elevated in comparison with never-smokers, even after many years of abstinence from smoking. The most comprehensive study in this respect was the large study of male UK doctors, which published results from 50 yrs of observation in 2004 [55]. Survival analyses were carried out for all-cause mortality for never-smokers, continuing smokers and exsmokers by age at stopping smoking. Evidence of reverse causality was present when comparing mortality ratios (RR) for equal-age groups of quitters and continuing smokers since mortality risk was higher in quitters than in current smokers. However, by 1 yr after quitting, rates were already lower than in continuing smokers. For smokers in the oldest age group (75-84 yrs; longest duration of follow-up), the following annual mortality rates were found: 51.7, 53.1, 69.1, 78.9, and 112.2 per thousand males for never-smokers, smokers quitting at age 35-44, 45-54 and 55-64 yrs, and continuing smokers, respectively. The authors concluded that, for males born around 1920, smoking cessation at age 50 yrs halved the risk of premature death, and quitting at age 30 yrs conveyed the 
same risk as found in lifelong nonsmokers. Survival analyses were not performed for mortality due to COPD.

The Chinese studies deserve special comment as they all found higher rates of COPD mortality in ex- than current smokers. In all studies, the number of COPD deaths was small, and three of the studies had a follow-up of $<10 \mathrm{yrs}$. It is also highly probable that these studies are especially subject to reverse causality due to the early stage of the tobacco epidemic in China and the higher prevalence of COPD in never-smokers compared with that found in Western countries. Furthermore, these studies and the other studies presented with mortality due to COPD or other respiratory causes can all be subject to the biases discussed previously, and underreporting or misclassification of COPD on death certificates is likely to influence the associations between smoking cessation and mortality. Data from the Copenhagen City Heart Study [61] has previously been reported, in which only $25 \%$ of subjects with severe COPD at baseline had this disease registered on their death certificate, and, conversely, $50 \%$ of those with COPD as the primary cause of death exhibited a normal FEV1/ FVC at baseline. It is well known that COPD patients die primarily due to respiratory failure, cardiovascular disease and lung cancer, and it seems that there are some links between these comorbid conditions and COPD mortality beyond cigarette smoke, which complicate the studies of mortality in COPD epidemiology [62].

Most of the recent research on mortality and COPD has focused on ICSs. A pooling of seven randomised studies ( $\sim 5,000$ patients) found that ICS reduced COPD mortality by $27 \%$ relative to placebo, although none of the studies separately reached significance in favour of ICSs [63]. The beneficial effect, however, was particularly noticeable in exsmokers and females, and it is assumed that ICSs may potentially work better in ex-smokers than current smokers in COPD, through largely unknown mechanisms [64]. Surprisingly, the TORCH trial showed no survival benefit in patients randomised to ICSs alone.

\section{Conclusions}

Complete estimation of the effect of smoking cessation per se in patients with severe COPD is still difficult due to the limited data and methodological challenges. In studies of morbidity, rate of FEV1 decline is the most widely used outcome measure, but may not be sufficient to fully describe the effect of quitting smoking on COPD as a disease entity. Studies on mortality due to COPD (usually combined with other respiratory causes) are impeded by difficulties in ascertaining the cause of death and because of reverse causality, especially if the duration of follow-up is short. Nevertheless, on the basis of the available evidence, the following can be concluded.

In smokers aged $>35$ yrs with mild-to-moderate COPD, smoking cessation initially increases the FEV1, and, subsequently, the rate of FEV1 decline in sustained quitters reverts to the age-related decline seen in never-smokers in the background population. However, the deficit in percentage predicted FEV1 at the time of smoking cessation is not fully recovered.

The majority of studies in patients with more severe disease confirm an attenuated rate of FEV1 decline following smoking abstinence compared with continuing smoking, and two studies suggest a greater benefit in females who quit smoking.

The few large observational studies with a long follow-up period suggest that smoking cessation decreases the RR (relative to continued smoking) of incident COPD and hospital admission with a COPD exacerbation. The risk reduction varies with duration of smoking cessation and cumulative tobacco exposure (pack-years of smoking).

Data from the USA and Europe indicate that smoking cessation leads to decreased mortality due to COPD and all causes compared with continued smoking.

In earlier studies, mortality rates due to COPD were paradoxically elevated in ex-smokers compared with current smokers for up to $10 \mathrm{yrs}$ after smoking cessation, but decreased thereafter. Many recent studies have not been of sufficient size or strength to clarify this issue, and reverse causality can also lead to underestimation of the benefits of cessation, even in studies that have shown some benefits. The available data show a permanently increased risk of morbidity and mortality due to COPD in ex-smokers compared with never-smokers.

Further research is needed, especially in China and other populations in whom the tobacco epidemic is at an early stage and in whom the chronic obstructive pulmonary disease prevalence in nonsmokers is higher than that found in developed countries.

\section{REFERENCES}

1 Mannino DM, Buist AS. Global burden of COPD: risk factors, prevalence, and future trends. Lancet 2007; 370: 765-773.

2 World Health Organization. Chronic Respiratory Diseases. Burden. www.who.int/respiratory/copd/burden/en Date last accessed: June 1, 2008. Date last updated: May 20, 2008.

3 Celli BR, MacNee W. Standards for the diagnosis and treatment of patients with COPD: a summary of the ATS/ ERS position paper. Eur Respir J 2004; 23: 932-946.

4 Rabe KF, Hurd S, Anzueto A, et al. Global strategy for the diagnosis, management, and prevention of chronic obstructive pulmonary disease. GOLD executive summary. Am J Respir Crit Care Med 2007; 176: 532-555.

5 Rabe KF, Beghe B, Luppi F, Fabbri LM. Update in chronic obstructive pulmonary disease 2006. Am J Respir Crit Care Med 2007; 175: 1222-1232.

6 Willemse BW, Postma DS, Timens W, ten Hacken NH. The impact of smoking cessation on respiratory symptoms, lung function, airway hyperresponsiveness and inflammation. Eur Respir J 2004; 23: 464-476.

7 Anthonisen NR, Connett JE, Kiley JP, et al. Effects of smoking intervention and the use of an inhaled anticholinergic bronchodilator on the rate of decline of FEV1. The Lung Health Study. JAMA 1994; 272: 1497-1505.

8 Anthonisen NR, Connett JE, Murray RP. Smoking and lung function of Lung Health Study participants after 11 years. Am J Respir Crit Care Med 2002; 166: 675-679.

9 Scanlon PD, Connett JE, Waller LA, Altose MD, Bailey WC, Buist AS. Smoking cessation and lung function in 
mild-to-moderate chronic obstructive pulmonary disease. The Lung Health Study. Am J Respir Crit Care Med 2000; 161: 381-390.

10 US Department of Health and Human Services. The Health Benefits of Smoking Cessation: a Report of the Surgeon General. DHHS Publication No. (CDC) 90-8416. Rockville, US Department of Health and Human Services, Public Health Service, Center for Chronic Disease Prevention and Health Control, Office on Smoking and Health, 1990.

11 International Agency for Research on Cancer, World Health Organization. Handbooks of Cancer Prevention. Volume 11. Tobacco Control. Reversal of Risk After Quitting Smoking. Lyon, International Agency for Research on Cancer, 2007.

12 Anthonisen NR, Wright EC, Hodgkin JE. Prognosis in chronic obstructive pulmonary disease. Am Rev Respir Dis 1986; 133: 14-20.

13 Hughes JA, Hutchison DC, Bellamy D, Dowd DE, Ryan KC, Hugh-Jones P. The influence of cigarette smoking and its withdrawal on the annual change of lung function in pulmonary emphysema. Q J Med 1982; 51: 115-124.

14 Postma DS, De Vries K, Koeter GH, Sluiter HJ. Independent influence of reversibility of air-flow obstruction and nonspecific hyperreactivity on the long-term course of lung function in chronic air-flow obstruction. Am Rev Respir Dis 1986; 134: 276-280.

15 Fletcher C, Peto R. The natural history of chronic airflow obstruction. BMJ 1977; 1: 1645-1648.

16 Buist AS, Nagy JM, Sexton GJ. The effect of smoking cessation on pulmonary function: a 30-month follow-up of two smoking cessation clinics. Am Rev Respir Dis 1979; 120: 953-957.

17 Anthonisen NR, Connett JE, Enright PL, Manfreda J. Hospitalizations and mortality in the Lung Health Study. Am J Respir Crit Care Med 2002; 166: 333-339.

18 Kanner RE, Anthonisen NR, Connett JE. Lower respiratory illnesses promote FEV1 decline in current smokers but not ex-smokers with mild chronic obstructive pulmonary disease: results from the Lung Health Study. Am J Respir Crit Care Med 2001; 164: 358-364.

19 Makris D, Moschandreas J, Damianaki A, et al. Exacerbations and lung function decline in COPD: new insights in current and ex-smokers. Respir Med 2007; 101: 1305-1312.

20 Kessler R, Faller M, Fourgaut G, Mennecier B, Weitzenblum E. Predictive factors of hospitalization for acute exacerbation in a series of 64 patients with chronic obstructive pulmonary disease. Am J Respir Crit Care Med 1999; 159: 158-164.

21 Garcia-Aymerich J, Monso E, Marrades RM, et al. Risk factors for hospitalization for a chronic obstructive pulmonary disease exacerbation. EFRAM study. Am J Respir Crit Care Med 2001; 164: 1002-1007.

22 Burchfiel CM, Marcus EB, Curb JD, et al. Effects of smoking and smoking cessation on longitudinal decline in pulmonary function. Am J Respir Crit Care Med 1995; 151: 1778-1785.

23 Pelkonen M, Notkola I-L, Tukiainen H, Tervahauta M, Tuomilehto J, Nissinen A. Smoking cessation, decline in pulmonary function and total mortality: a 30 year follow up study among the Finnish cohorts of the Seven Countries Study. Thorax 2001; 56: 703-707.
24 Lindberg A, Larsson LG, Rönmark E, Jonsson AC, Larsson K, Lundbäck B. Decline in FEV1 in relation to incident chronic obstructive pulmonary disease in a cohort with respiratory symptoms. COPD 2007; 4: 5-13.

25 Mannino DM, Reichert MM, Davis KJ. Lung function decline and outcomes in an adult population. Am J Respir Crit Care Med 2006; 173: 985-990.

26 Mannino DM, Davis KJ. Lung function decline and outcomes in an elderly population. Thorax 2006; 61: 472-477.

27 Tashkin DP, Clark VA, Coulson AH, et al. The UCLA population studies of chronic obstructive respiratory disease. VIII. Effects of smoking cessation on lung function: a prospective study of a free-living population. Am Rev Respir Dis 1984; 130: 707-715.

28 Sherrill DL, Holberg CJ, Enright PL, Lebowitz MD, Burrows B. Longitudinal analysis of the effects of smoking onset and cessation on pulmonary function. Am J Respir Crit Care Med 1994; 149: 591-597.

29 Godtfredsen NS, Vestbo J, Osler M, Prescott E. Risk of hospital admission for COPD following smoking cessation and reduction: a Danish population study. Thorax 2002; 57: 967-972.

30 Lindberg A, Jonsson AC, Rönmark E, Lundgren R, Larsson LG, Lundbäck B. Ten-year cumulative incidence of COPD and risk factors for incident disease in a symptomatic cohort. Chest 2005; 127: 1544-1552.

31 Lokke A, Lange P, Scharling H, Fabricius P, Vestbo J. Developing COPD: a 25 year follow up study of the general population. Thorax 2006; 61: 935-939.

32 Rogot E, Murray JL. Smoking and causes of death among U.S. veterans: 16 years of observation. Public Health Rep 1980; 95: 213-222.

33 Kanner RE, Renzetti AD Jr, Stanish WM, Barkman HW Jr, Klauber MR. Predictors of survival in subjects with chronic airflow limitation. Am J Med 1983; 74: 249-255.

34 Postma DS, Gimeno F, van der Weele LT, Sluiter HJ. Assessment of ventilatory variables in survival prediction of patients with chronic airflow obstruction: the importance of reversibility. Eur J Respir Dis 1985; 67: 360-368.

35 Anthonisen NR, Skeans MA, Wise RA, Manfreda J, Kanner RE, Connett JE. The effects of a smoking cessation intervention on 14.5-year mortality: a randomized clinical trial. Ann Intern Med 2005; 142: 233-239.

36 Hersh CP, DeMeo DL, Al Ansari E, et al. Predictors of survival in severe, early onset COPD. Chest 2004; 126: 1443-1451.

37 Doll R, Peto R, Wheatley K, Gray R, Sutherland I. Mortality in relation to smoking: 40 years' observations on male British doctors. BMJ 1994; 309: 901-911.

38 Ben Shlomo Y, Smith GD, Shipley MJ, Marmot MG. What determines mortality risk in male former cigarette smokers? Am J Public Health 1994; 84: 1235-1242.

39 Carstensen JM, Pershagen G, Eklund G. Mortality in relation to cigarette and pipe smoking: 16 years' observation of 25,000 Swedish men. J Epidemiol Community Health 1987; 41: 166-172.

40 Kuller LH, Ockene JK, Meilahn E, Wentworth DN, Svendsen KH, Neaton JD. Cigarette smoking and mortality. MRFIT Research Group. Prev Med 1991; 20: 638-654.

41 Marcus EB, Buist AS, Maclean CJ, Yano K. Twenty-year trends in mortality from chronic obstructive pulmonary 
disease: the Honolulu Heart Program. Am Rev Respir Dis 1989; 140: S64-S68.

42 Tockman MS, Comstock GW. Respiratory risk factors and mortality: longitudinal studies in Washington County, Maryland. Am Rev Respir Dis 1989; 140: S56-S63.

43 Tverdal A, Thelle D, Stensvold I, Leren P, Bjartveit K. Mortality in relation to smoking history: 13 years' followup of 68,000 Norwegian men and women 35-49 years. J Clin Epidemiol 1993; 46: 475-487.

44 Sunyer J, Lamarca R, Alonso J. Smoking after age 65 years and mortality in Barcelona, Spain. Am J Epidemiol 1998; 148: 575-580.

45 Lange P, Nyboe J, Appleyard M, Jensen G, Schnohr P. Relationship of the type of tobacco and inhalation pattern to pulmonary and total mortality. Eur Respir J 1992; 5: 1111-1117.

46 Pelkonen M, Tukiainen $\mathrm{H}$, Tervahauta M, et al. Pulmonary function, smoking cessation and 30 year mortality in middle aged Finnish men. Thorax 2000; 55: 746-750.

47 Godtfredsen NS, Holst C, Prescott E, Vestbo J, Osler M. Smoking reduction, smoking cessation, and mortality: a 16year follow-up of 19,732 men and women from the Copenhagen Centre for Prospective Population Studies. Am J Epidemiol 2002; 156: 994-1001.

48 Knuiman MW, James AL, Divitini ML, Ryan G, Bartholomew HC, Musk AW. Lung function, respiratory symptoms, and mortality: results from the Busselton Health Study. Ann Epidemiol 1999; 9: 297-306.

49 Engstrom G, Hedblad B, Janzon L, Valind S. Respiratory decline in smokers and ex-smokers - an independent risk factor for cardiovascular disease and death. I Cardiovasc Risk 2000; 7: 267-272.

50 Mannino DM, Buist AS, Petty TL, Enright PL, Redd SC. Lung function and mortality in the United States: data from the First National Health and Nutrition Examination Survey follow up study. Thorax 2003; 58: 388-393.

51 Ho SC, Zhan SY, Tang JL, Chan SG, Woo J. Smoking and mortality in an older Chinese cohort. J Am Geriatr Soc 1999; 47: 1445-1450.
52 Hsu HC, Pwu RF. Too late to quit? Effect of smoking and smoking cessation on morbidity and mortality among the elderly in a longitudinal study. Kaohsiung J Med Sci 2004; 20: 484-491.

53 Lam TH, He Y, Shi QL, et al. Smoking, quitting, and mortality in a Chinese cohort of retired men. Ann Epidemiol 2002; 12: 316-320.

54 Lam TH, Li ZB, Ho SY, et al. Smoking, quitting and mortality in an elderly cohort of 56,000 Hong Kong Chinese. Tob Control 2007; 16: 182-189.

55 Doll R, Peto R, Boreham J, Sutherland I. Mortality in relation to smoking: 50 years' observations on male British doctors. BMJ 2004; 328: 1519.

56 Doll R, Gray R, Hafner B, Peto R. Mortality in relation to smoking: 22 years' observations on female British doctors. BMJ 1980; 280: 967-971.

57 Ebi-Kryston KL. Predicting 15 year chronic bronchitis mortality in the Whitehall Study. J Epidemiol Community Health 1989; 43: 168-172.

58 Hansell AL, Walk JA, Soriano JB. What do chronic obstructive pulmonary disease patients die from? A multiple cause coding analysis. Eur Respir J 2003; 22: 809-814.

59 Gamble E, Grootendorst DC, Hattotuwa K, et al. Airway mucosal inflammation in COPD is similar in smokers and ex-smokers: a pooled analysis. Eur Respir J 2007; 30: 467-471.

60 Calverley PM, Anderson JA, Celli B, et al. Salmeterol and fluticasone propionate and survival in chronic obstructive pulmonary disease. $N$ Engl J Med 2007; 356: 775-789.

61 Jensen HH, Godtfredsen NS, Lange P, Vestbo J. Potential misclassification of causes of death from COPD. Eur Respir J 2006; 28: 781-785.

62 Sin DD, Anthonisen NR, Soriano JB, Agusti AG. Mortality in COPD: role of comorbidities. Eur Respir J 2006; 28: 1245-1257.

63 Sin DD, Wu L, Anderson JA, et al. Inhaled corticosteroids and mortality in chronic obstructive pulmonary disease. Thorax 2005; 60: 992-997.

64 Soriano JB, Sin DD, Zhang X, et al. A pooled analysis of FEV1 decline in COPD patients randomized to inhaled corticosteroids or placebo. Chest 2007; 131: 682-689. 